\title{
CERTAIN $L^{p}$ BOUNDS FOR ROUGH SINGULAR INTEGRALS
}

\author{
KhadiJA Al-Balushi AND Ahmad Al-SALman
}

Abstract. In this paper, we prove $L^{p}$ bounds for singular integrals with rough kernels associated to certain surfaces. Our results extend as well as improve previously obtained results.

Mathematics subject classification (2010): 42B20, 42B15, 42B25.

Keywords and phrases: singular integrals; rough kernels; maximal functions; surfaces of revolution.

\section{REFERENCES}

[1] A. Al-Salman, Marcinkiewicz functions along flat surfaces with hardy space kernels, J. Integral Equations Appl. 17 (4) (2005), 357-373.

[2] A. Al-Salman, Y. PAn, Singular integrals with rough kernels in $\operatorname{Llog}^{+} L\left(\mathbb{S}^{n-1}\right)$, J. London. Math. Soc. (2) 66 (2002) 153-174.

[3] A. Al-Salman, Y. Pan, Singular integrals with rough kernels, Canad. Math. Bull. Vol. 47 (1), (2004), 3-11.

[4] A. Al-SAlman, Estimates of singular integral operators of convolution type with rough kernels, University of Pittsburgh (1999) (PhD dissertation).

[5] A. P. Calderón, A. Zygmund, On existence of certain singular integrals, Acta. Math. 88 (1952), $85-139$.

[6] A. P. Calderón, A. Zygmund, On singular integrals, Amer. J. Math. 18 (1956), 289-309.

[7] L. CHENG AND Y. PAN, $L^{p}$ bounds for singular integrals associated to surfaces of revolution, J. Math. Anal. Appl. 265 (2002), 163-169.

[8] W. C. ConnetT, Singular integrals near $L^{1}$, Proc. Sympos. Pure Math. of the Amer. Math. Soc., (eds., S. Wainger and G. Weiss), 35 (1979), 163-165.

[9] J. DUOANDikoETXEA AND J. L. RUBio DE FRANCIA, Maximal and singular integral operators via Fourier transform estimates, Invent. Math. 84 (1986), 541-561.

[10] D. FAN, K. GUO, AND Y. PAN, A note of a rough singular integral operators, Math. Inequal. Appl. 2 (1999), 73-81

[11] D. FAN, K. GUO, AND Y. PAN, $L^{p}$ estimates for singular integrals associated to homogeneous surfaces, J. Reine Angew. Math. 542 (2002), 1-22.

[12] L. GRAFAKOS AND A. STEFANOV, $L^{p}$ bounds for singular integrals and maximal singular integrals with rough kernels, Indiana Univ. Math. J. 47 (1998), 455-469.

[13] W. Kim, S. WAinger, J. Wright AND S. ZieSLer, Singular integrals and Maximal functions associated to surfaces of revolution, Bull. London Math. Soc. 28 (1996), 291-296.

[14] Y. PAN, L. TANG AND D. YANG, Boundedness of singular integrals with rough kernels along surfaces of revolution, Adv. Math. (China) 2003, 32, 677-682.

[15] F. Ricci And G. Weiss, A characterization of $H^{1}\left(S^{n-1}\right)$, Proc. Sympos. Pure Math. of Amer. Math. Soc., (eds., S. Wainger and G. Weiss), 35 (1979), 289-294.

[16] E. M. Stein, Harmonic Analysis: Real-Variable Method, Orthogonality and Oscillatory Integrals, Princeton Univ. Press, Princeton, NJ, 1993. 